\title{
Engineering Final Project Supervised in an Adaptive Way With Moodle Support
}

\author{
Javier Esteban-Escaño, Ana Lucía Esteban-Sánchez, and María Luisa Sein-Echaluce
}

\begin{abstract}
For the current engineering degrees, it is necessary to design a monitoring process in order to supervise the subject called "Final Degree Project." This method must be able to manage and evaluate the process of completing the project and submitting the documentation. This paper describes the design of an adaptive method and how to put this mechanism into practice using the learning management system Moodle. Adaptivity provides the chance to study different scenarios that can be produced in cooperation with students and their tutors. The conclusions of this paper show a high level of satisfaction with the adaptive method used in the subject.
\end{abstract}

Index Terms - Engineering education, educational technology, adaptive systems, engineering, collaborative tools.

\section{INTRODUCTION}

$\mathbf{S}$ TUDENTS of Spanish engineering degrees traditionally have completed their studies with the realisation of a Final Project (FP) [1], as opposed to degrees in other areas, which do not include that subject. With the implementation of the European Higher Education Area (EHEA), the Final Degree Project (FDP) course was joined to new studies (called degrees), which began around the year 2008. In the case of engineering, an adaptation of the traditional FP was made, including characteristics of previous EHEA subjects, as continuous assessment to achieve that our students acquire new skills.

The new university degree system aims, among other things, to control better the amount of work and time that the students spend on any subject and, in particular, the FDP. The methodologies' continuous assessment (formative and summative) has been incorporated throughout the process, but we must take into account the special features that the new subject FDP presents (similar to the old FP):

- There is an absence of officially scheduled class sessions (no traditional lectures).

- Each student is guided by a tutor during the course of the FDP.

- The final FDP product is evaluated by a tribunal of teachers.

Manuscript received October 24, 2016; revised December 12, 2016; accepted December 23, 2017. Date of publication January 20, 2017; date of current version March 17, 2017.

J. Esteban-Escaño and A. L. Esteban-Sánchez are with the Escuela Universitaria Politécnica de La Almunia, University of Zaragoza, 50009 Zaragoza, Spain, and also with the GIDTIC Research Group, University of Zaragoza, 50009 Zaragoza, Spain (e-mail: javeste@unizar.es; anaeste@unizar.es).

M. L. Sein-Echaluce is with Applied Mathematics Department, University of Zaragoza, 50009 Zaragoza, Spain, and also with the GIDTIC Research Group, University of Zaragoza, 50009 Zaragoza, Spain (e-mail: mlsein@unizar.es).

Color versions of one or more of the figures in this paper are available online at http://ieeexplore.iee.org.

Digital Object Identifier 10.1109/RITA.2017.2655178
- It is usually the last subject that the student must face, and sometimes there are external factors to bear in mind, such as concurrency with professional activities.

If any subject in the learning process is personal to each student, the special characteristics of the FDP subject emphasise the need for personalisation in learning.

In that sense, a concern for the design and improvement of the FP realisation process has always existed [2]-[4], and that attitude is maintained for the FDP, both in the design of good practices for the realisation [5], [6] and the evaluation [7], [8] of the process.

Amongst the technological advances that have helped carry out this customisation according to the profile, rates and progress of students, the adaptive hypermedia systems have left the most evidence of success [9]-[13]. These systems facilitate the cognitive learning process of students in any context and, at the same time, help teachers carry out a methodology adapted to the requirements and needs of each student whose application is complicated in the traditional teaching sense. Amongst all the experiences in the implementation of adaptive systems, this paper highlights those found in the field of university education: content design with the help of learning management systems (LMS) [14], [15], in the creation and management of adaptivity contents [16], [17], and nowadays, in massive open online courses (MOOCs) in order to suit the special characteristics of massiveness and heterogeneity of participants by models [18], [19] and e-learning platforms [14], [15], [17], [20]. In this environment, where personalised attention to students involves a great amount of effort for teachers, automated adaptive teaching presents clear advantages by enabling them to provide such attention more effectively (better results) and more efficiently (less effort).

Moreover, in relation to the monitoring process in the realisation of the FDP, this paper highlights the methodology designed by the group of interest in faculty innovation at university GI-IDES (Catalonian abbreviation) Group FDP [21], which forms the basis of this proposal. Such a method has been adapted to the context of this work-besides emphasising its implementation of LMS Moodle as the main feature [22].

The overall goal of the method here proposed is to help students obtain better results at the end of the teachinglearning process during the development of the FDP. The specific objectives of this experience are:

- to understand how the students of the FDP subject are facing an adaptive learning system and to determine the abilities that adaptivity brings them when completing their assignments;

- to generate useful information for the responsibility of the FDP course from the acquired knowledge which 


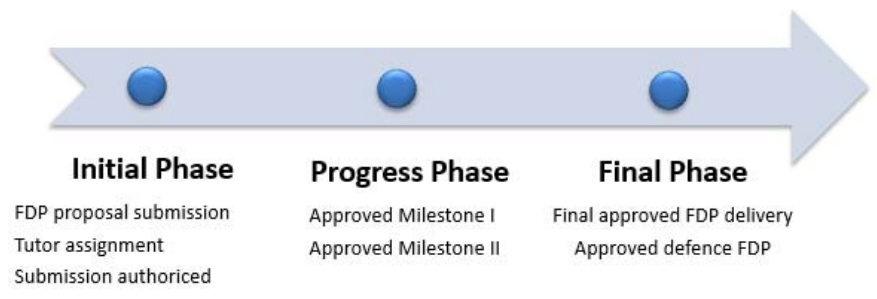

Fig. 1. Phases and main activities of the FDP.

facilitates decision making in implementing adaptive learning strategies, using those which have been proven most useful for teaching students; and

- to discover the weaknesses of the current process.

The following pages will expose the methodological framework and technology for which the work process and the information system used is contextualised. Then, the investigation design and the results will be examined. Finally, the conclusions from this adaptive experience will be revealed.

\section{Methodological Framework}

The personal situation of each student will determine when he or she will begin the FDP and what their specific commitment will be. Therefore, it is necessary to adopt a methodology that is common to all students but, at the same time, flexible in the monitoring and evaluation of activities. A methodology that suits the rate of the student, his or her preferences and needs, as well as all profiles of the different roles involved, is what is proposed in this method.

Obviously, this methodology involves the students enrolled in the FDP course and the teachers who perform the guidance and mentoring during the process of the FDP (hereafter, called tutors) and listed as academically responsible for the final product, the FDP.

The method of completing the FDP is structured into three broad phases, which are detailed below, and whose sequential execution is indicated in [23, Fig. 1]:

- Initial Phase: Evaluation of the FDP proposal by the tutor. The student submits a proposal (brief summary and objectives) on the theme of the FDP they want to do. The coordinator, according to the theme proposed by the student, assigns a tutor to the student. Then, the student must prepare a document summarising the work to be done, the planning thereof and a previous study of the state of the art in the field in which the FDP will develop. This document is reviewed by their tutor, to clarify or adjust features of their work, and only after acceptance, can the student move to the next phase of work.

- Progress Phase: The work is performed, and a monitoring and evaluation of the achievements in the FDP are made. This phase contains the development work, mentoring and evaluation of the different intermediate achievements that the student must overcome (continuous assessment: formative and summative). The student performs two intermediate deliveries called "Milestone I" and "Milestone II", which are qualified by the tutor. Before the completion of each milestone, the tutor provides advice and guidance and, after their implementation,

\begin{tabular}{|llll}
\hline Start & 1st call $>$ 2nd call & 3rd call \\
\hline Initial $\bigcirc$ Progress $\bigcirc$ Final & \\
Initial & Progress $\bigcirc$ Final & \\
Initial & & Progress & Final \\
Initial & & Progress \\
\hline
\end{tabular}

Fig. 2. Time limits for delivery of FDP work.

provides feedback within the most conflictive points or errors that will be corrected for the next delivery. Passing Milestone I will allow the student to begin Milestone II.

- Final phase: The evidences generated during the performance of the FDP are documented and collected, ending with its oral presentation. In this phase, the student performs the final delivery of the FDP, which must contain the final report, the required additional documents, and a poster that summarises the work presented. The tutor evaluates this material and proposes a grade. If the assessment is positive, the tutor authorises the student to deliver the FDP for its evaluation and oral defence before a tribunal. The process ends when the student makes an oral presentation of the FDP before the tribunal in one of the three possible calls. The final grade of the FDP is obtained from the grades of the tutor throughout the phase's progress (Milestone I and Milestone II), the grades awarded by the tribunal for both written submissions and the FDP's public defence.

In addition to the working methods already discussed, training is provided to students at the beginning of the semester about useful resources for carrying out their FDP:

- Training in the methodology and technology that supports the FDP is explained.

- Training tools for content generation include:

$\circ$ use of automated templates in OpenOffice and Microsoft Office formats for the documents: final report, and annexes [24];

○ Zotero [25] as a reference manager; and

O use of templates in order to create the poster [24].

The desirable period for the three phases of the method would begin at the beginning of the semester and end on the first call in June. But sometimes the students finish their FDP in second or third call, or even fail to finish and must present it at the next academic year (Figure 2). This work presents the process of the FDP in this circumstance, which can be adapted to any other academic regulations.

As already mentioned, this work is based on the methodology designed by the GI-IDES Group [21], but in the current design the activity of the "oral presentation of the proposal" was eliminated in the initial phase as redundant, and also has updated some indicators and items of the used rubrics in the evaluation activities of the different phases. Furthermore, in this proposal, LMS Moodle is included as the technology that supports each stage of the process.

\section{TECHNOLOGY FRAMEWORK}

In the proposed methodology, the various activities included in the phases of the FDP's realisation must have a sequence 
that suits the different student rhythms and concerns, which will be referred to as temporal adaptivity. On the other hand, the resources that both roles generate in the activities of implementation and evaluation and during communication between them (documents, messages and grades)—as well as the necessary information that must be organised and made available to the students in a personalised way according to their different profiles - will be referred to as the adaptivity of profiles. For this reason, the Moodle platform that acts as a LMS is used to organise the generated knowledge and provides tools for the different types of adaptivity.

In other experiences, new modules (plugins) have been developed for Moodle. These are designed specifically to manage the FDP [26], but lead to raise the cost of maintenance and the need to updates for future versions of Moodle. This proposal uses only the parts of a basic installation of Moodle, facilitating transferability and sustainability of the proposed method.

The basic elements of Moodle allow to create a virtual course with the informative and interactive elements needed to implement this method:

- static—book, tags, URLs, folders and documents;

- interaction-forums, messaging, tasks and surveys;

- management of participants-clusters and groups; and

- evaluation-direct qualification and qualification by rubrics on tasks.

In the Moodle course (which will be referred to as the virtual course) created in this experience, apart from student tutors and teachers, the figure of the professor responsible for the FDP subject (or "coordinator") is also included. The latter's main functions are: to apply the adaptivity in the virtual course, provide the necessary training on the process and provide useful resources of interest to the students and their tutors (rules, deadlines and material provided in workshops on methodology and creating resources, etc.).

\section{A. Adaptivity Applied in the Design of the Virtual Course}

Moodle provides mechanisms to configure adaptivity easily within their courses. Thus, the temporal adaptivity is implemented through access restrictions, dependent on overcoming or termination of other resources. Also, adaptivity profiles are achieved by controlling the membership to groups and clusters.

The following explains the virtual course design, taking into account the adaptivity in the temporary access to resources and activities and access to information and communication according to profiles.

1) Temporary Adaptivity: To organise the work phases (Initial, Progress and Final), restriction of access to resources and activities that make up each phase is applied. The resources and activities become visible, depending on whether the students accessed certain resources or they obtained a minimum grade on previous activities. In this way, overcoming the "Initial Proposal" makes the Progress Phase visible, within which the task to deliver is Milestone I. In turn, overcoming Milestone I makes the task to deliver of Milestone II visible. Finally, overcoming Milestone II makes the Final Phase visible (Figure 3).

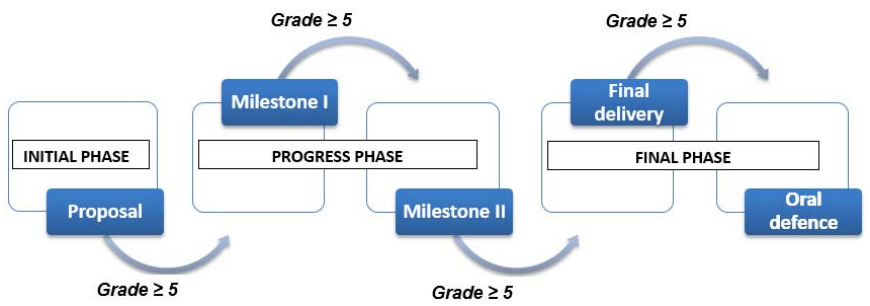

Fig. 3. Temporary adaptability of the FDP.

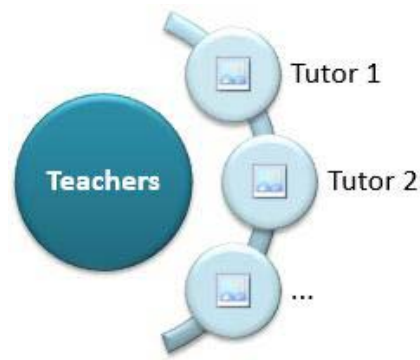

Fig. 4. Teachers cluster.

Access to resources and activities has an adaptive time design, so that the progression and improvement of the proposed activities allows the student to advance in the FDP stages established in the virtual course. In this way, the process is rigorous in terms of the obligation to pass a review by the tutors of the FDP (formative and summative evaluation). Yet, at the same time, it is flexible as to the temporary location in which these phases are delivered, but that requires coordinated planning between tutor and student. The great beneficiary of this design is the student, as the process is adapted to his or her rate of progress in the implementation of the FDP's various activities.

2) Adaptivity for Roles: In order to have points of information and independent media for different groups, access is controlled through membership in "groups/clusters", in combination with the access restrictions (own tools in Moodle). Several clusters are created, called: teachers, tribunal and graduates.

- Teacher cluster (Figure 4): The tutors have their own section in the virtual course, which aims to provide a point of communication and a repository of resources only visible for teachers.

- Tribunal cluster (Figure 5): Each tribunal in the virtual course contains the groups formed by each tutor and their students. The configuration of the forum "tribunal", with the option of separate groups, allows having a point of communication and private collaboration between each tutor and their students .

- Graduates cluster (Figure 6): The students who have passed their FDP are included in this cluster, with the aim of allowing access to the final satisfaction survey.

The virtual course centralises the work point and the communication between all those involved in the FDP. The application of adaptivity by roles provides the advantage of channelling the activities and messaging groups, so that all notices of the activity in the course only reach its addressees and not all participants. 


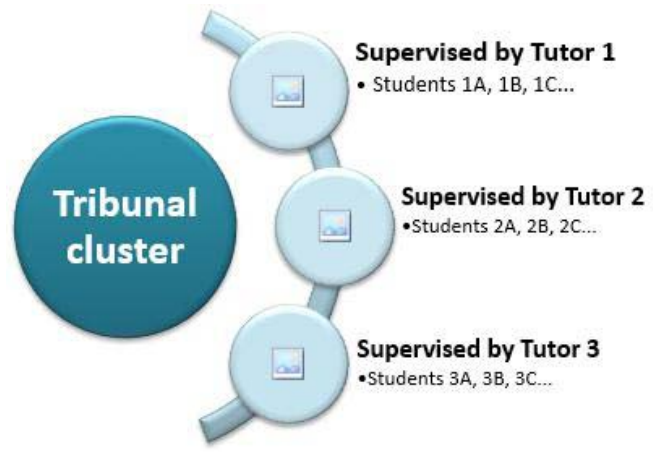

Fig. 5. Cluster and groups tribunals.

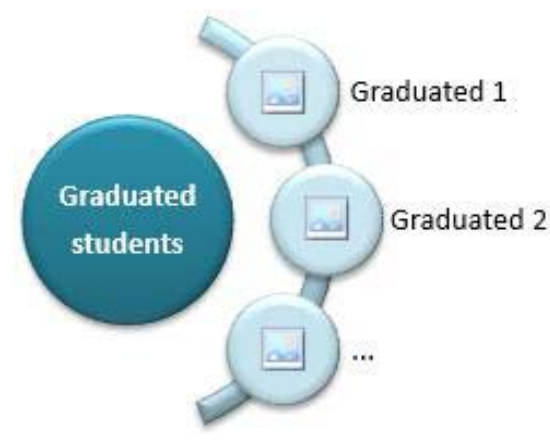

Fig. 6. Graduated students.

The use of the virtual course involves technological support for the methodological framework discussed above. The goal is to guide both students and tutors through the different phases of the process. On the one hand, in order to personalise the learning process, a concordance of the pace and progress of the students and their tutors, as well as their profiles, must be maintained. On the other hand, the virtual course allows the unification of the methodology work and continuous evaluation (formative and summative) in the FDP, which will result in improvements in the final evaluation of the tribunals. Although all students must perform the same sequence of phases, each of them decides when to perform them.

\section{Research Design}

\section{A. Research Context}

The proposed method was applied during the 2013-14 and 2014-15 academic years for the final grade subjects, in studies Mechatronics Engineering and Engineering in Industrial Organization, taught at the Escuela Universitaria Politécnica La Almunia, Polytechnic School La Almunia (EUPLA) at the University of Zaragoza.

In both cases, the FDP subject allocated 12 credits (European Credit Transfer and Accumulation System (ECTS), and was situated in the second half of the fourth year. Three calls for submission of the FDP (June, September and December) were offered. Work on the subject of the FDP was initially proposed for a period of 20 weeks, but it could be extended up to eleven months in the event of the third call.

Moreover, it should be highlighted that, in this particular experience, the tutors were involved in the evaluation process, hence the use of this terminology in one of the clusters.
The monitoring process in the FDP development and the use of the virtual course are objects of interest in the research design described below.

\section{B. Research Design}

A case study was considered [27], [28], combining quantitative and qualitative techniques as a research design in order to observe the degree of satisfaction by the students and their tutors, once they passed the FDP with the applied methodology.

The research work began in the 2013-14 academic year. The methodology was described in a previous conference [29], where the first results were presented by the authors of the current study. The current paper incorporates the 2014-15 academic year data into the quantitative part of the study and includes the qualitative part of the research, such as interviews with the actors in the process. This paper also combines the results of both works.

1) Quantitative Technique: For the quantitative approach of the study, an adaptation of the satisfaction questionnaire survey, Constructivist On-Line Learning Environment Survey (COLLES), was performed with a dual purpose: first, to collect information about the accurate design of the FDP subject and, second, to get data about the research interest. The design of the questionnaire was an extension of the FDP satisfaction survey by the University of Cadiz [30]. The survey consists of a Likert scale of five levels, for a total of 28 questions grouped in five blocks:

- 8 about how they conducted their FDP;

- 3 about the temporal schedule of the subject;

- 6 about the virtual course organisation;

- 3 about the tutorial development; and

- 4 about the motivation and satisfaction gained through the implementation of the FDP.

The participation for graduates in the survey was:

- $12.5 \%$ of a total of 16 students graduated in Mechatronics Engineering in the 2014-15 academic year.

- $65 \%$ of a total of 20 students graduated in Industrial Organization Engineering in the 2013-14 academic year.

- $42.8 \%$ of a total of 7 students graduated in Industrial Organization Engineering in the 2014-15 academic year.

2) Qualitative Technique: For the qualitative approach, an in-depth interview technique was used, since this datacollection system facilitates the interaction with study subjects and, through their narratives, helps determine how their strategies overcame the difficulties encountered during the application of the method.

Four students in Mechatronics Engineering and two in Industrial Organization Engineering were interviewed. Also, two tutors in Mechatronics and three in Industrial Organization were interviewed.

a) Assumptions taken in the research: This section describes the assumptions of the researchers who conducted the interview:

- The proposed adaptive method helps students organise their work in the realisation of the FDP.

- The technology used helps students and tutors implement the adaptive methodology. 
b) Centres of interest: The core interests in the research are:

- the influence the virtual course has had on temporary adaptability for students;

- the influence the virtual course has had on profile adaptability for students;

- the way in which students have perceived their passage through the virtual course; and

- the utility students found in the virtual course.

To structure the interview procedure, the following decisions were made:

- Number of interviews: One interview was conducted per participant.

- Transcripts of the interviews: A first authorisation was requested of storytellers. Then, the interview was recorded, and finally, a transcript of the recording was sent to the interviewee.

The questions used at the beginning of the deep interview were designed for this experience and reflect the study's core interest and research assumptions. (Some new questions surged from the interviews). These are the questions that were asked:

- Describe your experience in the development of the FDP.

- Did you participate in the organised workshops for FDP? What is your point of view?

- Did you find any help in the virtual course to perform your FDP?

- What do you think about the fact that a new activity wasn't visible until you finished the previous one?

- Did you find useful the basic information proposed in the virtual course (execution time, regulations, methodology, etc.)?

- If you have read the documentation that describes working with the methodology of the FDP, what do you think about it?

- Did you use the documents template of the FDP in the virtual course? What do you think about it? Do you use other templates?

- Were the resources related to the workshop and included in the virtual course useful for you?

- What resources have been missing from the virtual course?

- Has your tutor evaluated your deliverables on time?

- What was the nature of the relationship with your tutor while you were working on your FDP?

\section{RESULTS}

\section{A. Quantitative Results}

Figure 7 shows the average responses (from 1 to 5) organised by groups of questions.

The realised survey highlights the high level of satisfaction of the students, with a mean of 4.53 in the group of questions about the tutor's work, a mean of 4.26 in the questions about the FDP process, a mean of 4.09 in the satisfaction for doing the FDP, a mean of 3.9 about their temporal organisation while they were working on their FDP, and a mean of 3.8 about the use they made of the virtual course.

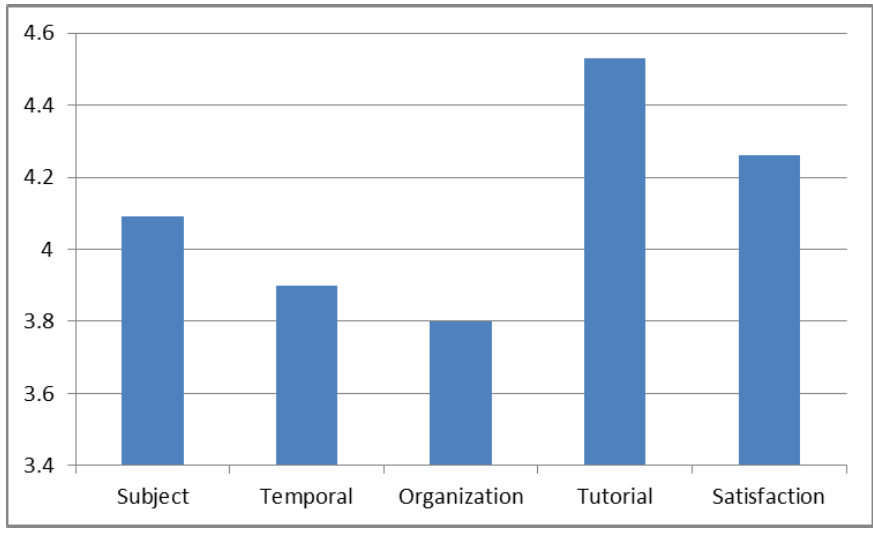

Fig. 7. Satisfaction survey in FPD process.

Going into greater detail:

- The question about the perceived utility of the personalised temporal access gained a mean of 4.2, which means they had a positive perception of the adaptivity system.

- The question whether they had enough information in the virtual course obtained a mean of 4.1, which means that the created design was perceived as useful by students.

- The question whether they found appropriate the different phases in which the work was divided gained a mean of 3.6, which means that students appreciated it, but they think that it can be improved.

- The question whether they knew the objectives of the FDP before starting it gained a mean of 3.3, which means that the initial phase was the hardest one for students.

Comparing the mean of the responses of the academic year 2013-14 and 2014-15 does not show significant differences using a Wilcoxon test with a p-value of $<0.01$. This suggests that, for both academic years, their perception was very similar.

\section{B. Qualitative Results}

From all the graduate students, this study chose students who presented their FDP in some of the calls of 2014-15 academic year, and $25 \%$ of the students that matched these conditions were interviewed. Four students in Mechatronics Engineering and two in Industrial Organization Engineering were interviewed. Also, two tutors in Mechatronics and three in Industrial Organization were interviewed.

A triangulation was made between the answers given by students and tutors to verify all data. These results, organised by categories, are shown hereafter: time management, contents in virtual course, FDP official information, tutorstudent relationship, documentation and training program.

- Time management: One of the core interests for the work is the influence that temporal adaptivity has had on students. The interviews confirm that students agree with the monitoring system, which prevents an activity from moving on until they have received positive feedback on the previous one and each of those deliveries has been evaluated as part of the continuous assessment of the subject. On the different phases of the FDP, both tutors and students indicated that the initial phase of establishing 
the objectives and methodology was one of the most timeconsuming phases for students.

- Contents in the virtual course: Overall, students have made more extensive use of the Moodle resources than the tutors, who used it only as a system for receiving and evaluating partial deliveries. Tutors find the use of Moodle easy as a technological resource, and they appreciate the possibility to consult other students' work. Students positively appreciated the presence of templates and external resources that provide them with information; they found especially useful the instructions about how to include references in documents. In contrast, the use of email was bigger than the messaging system of Moodle, whose use should be encouraged as a system of private communication between tutor and student, allowing centralised communication in one place.

- FDP official information (regulations, deadlines, etc.): Both teachers and students find it very useful and also like how it is offered. The access to the approved posters of the FDP in previous years has been controversial, with some students saying that they find them helpful, but others saying that the old posters confused them. This is perhaps because students can access the posters but they do not know the grade they received.

- Tutor-student relationship: In most cases, both teachers and students qualify this relationship as very satisfactory and the key to being successful in the FDP. The mentoring has been made, in most of the cases, in person, although the use of forums should be promoted for frequently asked questions. Students value that they are able to have as many meetings with their tutor as they need, and they say that there was high involvement of their tutor in achieving completion of the FDP, making some partial revisions before the final delivery in each milestone.

- Documentation and training program: Overall, the documentation and courses taken for developing the FDP seem useful, although many students surveyed were unable to attend the initial training.

\section{Improvement Plan as a Result of the Qualitative Study}

Here are some suggestions for improving the proposed method emerging from the interviews, which were found relevant, as they were confirmed by several participants in both groups:

- Time management: Some students and tutors have indicated the desirability of including more intermediate milestones (reviews) in the progress phase. Students suggest including a virtual course calendar with their work planning, which their tutor has approved in the initial phase, in order to follow its real progress. It is also suggested that deliveries have dates assigned according to the calls in order to have a clearer planning of the semester. Tutors and students believe that the time spent in assigning the FDP is excessively long, which is a significant delay for students presented on the first call, and they claim that they do not have enough time to follow the next phases in optimal conditions. (These impressions will be transferred to the EUPLA authorities to speed up the initial phase.)
- Contents in the virtual course: Students and teachers suggest adding selected examples of FDPs from previous years and including a calendar with delivery dates for Milestones I and II (progress phases) for each call.

- Tutor-student relationship: The satisfaction degree expressed by the students with their tutor is high, particularly in the feedback provided by the tutor in the qualifying process.

\section{CONCLUSIONS}

The practical application of the methodology previously proposed [21] has been achieved through giving concrete guidelines to carry it out in any context.

The combination of qualitative and quantitative techniques ensures that the obtained results reflect the perception of the actors in the process. As already shown quantitatively and qualitatively, the students are very satisfied with the process of carrying out their FDP, as well as with the mechanism of adaptivity included in the virtual course and with the tutorial action, consistent with other adaptive learning experiences [15], [31]. The division in phases of the realised work has been satisfactory for participants in the process who believe that the contents included in the virtual course are appropriated and useful. Finally, adaptivity in the content is also perceived favourably, as was demonstrated in a previous study by the Esteban Escaño et al. [29], yielding a correlation of 0.77 between the perception of the usefulness of the designed adaptivity and the overall satisfaction with the realised FDP.

On the basis of the goals set in this research, it can be said that students have accepted favourably the application of adaptivity in the virtual course. They consider the temporal adaptivity a good mechanism for the personalised guide in the FDP process. Adaptivity by user profiles is less valued by students than was expected, because everyone sees what matches their profile, but they do not know what the other users are seeing. Yet, if we do not apply this adaptivity, the virtual course would be saturated by information from all users. The teacher responsible for the virtual course can interpret the results obtained from the application of adaptivity as successful in both directions (temporal and profiles).

The proposed monitoring method for FDP development is sustainable because the technology that supports it (Moodle) is an open-source software and does not require further development, contrary to what was done in other studies [26]. Moreover, it is a transferable method to any area of knowledge, and the technology used is comprehensive and easy to use. Therefore, it can be used in different areas of engineering; only the absence of previous experience in FDP may cause difficulties in its application to the faculty.

Future work will consist of incorporating the proposed method, the improvement plan mentioned above. The authors also plan to improve the research technique with new instruments that provide a more detailed information system to monitor the FDP and allow demonstrating the positive impact of the method on students' learning. 


\section{ACKNOWLEDGMENTS}

The authors would like to thank the Government of Aragon and the European Social Fund for supporting this work.

\section{REFERENCES}

[1] A. P. Márquez, J. M. Gil, and Y. L. J. A. Rosado, "Hacia una metodología para el desarrollo de trabajos y Proyectos Fin de Carrera en Ingeniería Informática," in Proc. 13th Jornadas Enseñanza Univ. Inf., 2007, pp. 15-17.

[2] M. Á. M. Muñoz and J. M. M. Villaverde, "Nuevo enfoque multidisciplinar en el el proyecto fin de carrera en ingeniería civil. Experiencia en la UEM," REDU Rev. Docencia Univ., vol. 8, no. 2, pp. 117-128, 2010.

[3] J. F. Monllor, M. L. Á. López, J. V. Guarinos, S. B. Pérez, C. N. López, and A. B. Vázquez, "Aplicación de herramientas Web colaborativas en la realización de Proyectos Fin de Carrera en Ingeniería," in Proc. 8th Jorn. Redes Investig. Docencia Univ., 2010, pp. 1709-1721.

[4] J. J. O. Larrea, "Análisis y propuesta de mejora en la dirección de Proyectos de Fin de Carrera en Ingeniería Informática," Univ. Rioja, 2015. [Online]. Available: file://C:/Users/javier/Downloads/ Dialnet-AnalisisYPropuestaDeMejoraEnLaDireccionDeProyectos46009.pdf

[5] G. Estapé-Dubreuil et al., "Trabajos Fin de Grado: La coordinación como clave del éxito," in Proc. Rev. Congr. Int. Docència Univ. Innov. (CIDUI), vol. 1. 2012, pp. 1-22.

[6] D. Hernández-Leo et al., "Implementación de buenas prácticas en los Trabajos Fin de Grado," Rev. Docencia Univ., vol. 11, pp. 259-278, Nov. 2013.

[7] V. M. Oliver, D. Hernández-Leo, I. Camps i Pujolar, and J. M. Gallardo, "Uso de rúbricas para el seguimiento y evaluación de los trabajos fin de grado," in Proc. 2nd Congr. Int. Sobre Eval. Por Competencias Mediante Erúbricas, Oct. 2012.

[8] V. Moreno, G. Carpintero, and D. Hernández-Leo, "Dos casos del uso de rúbricas para la evaluación de Trabajos Fin de Grado," in Proc. 3rd Jorn. Innov. Educ. Ing. Telemática, Oct. 2013, pp. 1-7.

[9] B. de La Passardiere and A. Dufresne, "Adaptive navigational tools for educational hypermedia," in Proc. 4th Int. Conf. Comput. Assist. Learn., London, U.K., 1992, pp. 555-567.

[10] C. Kaplan, J. Fenwick, and J. Chen, "Adaptive hypertext navigation based on user goals and context," User Model. User-Adapt. Interact., vol. 3, no. 3, pp. 193-220, Sep. 1993.

[11] P. Brusilovsky, "Methods and techniques of adaptive hypermedia," User Model. User-Adapt. Interact., vol. 6, nos. 2-3, pp. 87-129, Jul. 1996.

[12] P. De Bra et al., "AHA! The adaptive hypermedia architecture," in Proc. 14th ACM Conf. Hypertext Hypermedia, 2003, pp. 81-84.

[13] A. J. Berlanga and F. J. García-Peñalvo. (2008). Learning Design in Adaptive Educational Hypermedia Systems, accessed on Mar. 3, 2016. [Online]. Available: http://gredos.usal.es/jspui/handle/10366/21699

[14] D. Lerís and M. L. Sein-Echaluce, "La personalización del aprendizaje: Un objetivo del paradigma educativo centrado en el aprendizaje," Arbor, vol. 187, no. 3, pp. 123-134, Dec. 2011.

[15] D. L. López, F. V. Muniesa, and Á. V. Gimeno, "Aprendizaje adaptativo en Moodle: Tres casos prácticos," Educ. Knowl. Soc., vol. 16, no. 4, p. 138, Dec. 2015.

[16] A. J. B. Flores and F. J. García-Pen̈alvo. (Sep. 17, 2005). IMS LD Reusable Elements for Adaptive Learning Designs, accessed on Mar. 3, 2016. [Online]. Available: http://gredos.usal.es/ xmlui/handle/10366/21710?show=full

[17] Á. Fidalgo-Blanco, F. J. García-Peñalvo, M. L. Sein-Echaluce, and M. Á. Conde-González, "Learning content management systems for the definition of adaptive learning environments," in Proc. Int. Symp. Comput. Edu. (SIIE), 2014, pp. 105-110.

[18] Á. F. Blanco, F. J. García-Peñalvo, and M. Sein-Echaluce, "A methodology proposal for developing adaptive cMOOC," in Proc. 1st Int. Conf. Technol. Ecosyst. Enhancing Multiculturality, 2013, pp. 553-558.

[19] N. Sonwalkar, "The first adaptive MOOC: A case study on pedagogy framework and scalable cloud architecture-Part I," MOOCs FORUM, vol. 1, no. P, pp. 22-29, Sep. 2013.
[20] $i M O O C$, accessed on Mar. 3, 2016. [Online]. Available: http://gridlab.upm.es/imooc/

[21] GRAU GI-IDES TFG. (2012). GI-IDES Materials | TFG, accessed on Feb. 21, 2016. [Online]. Available: http://grupsderecerca.uab.cat/gi-ides$\mathrm{tfg} /$ content/materials

[22] Moodle. (2016). Moodle-Open-Source Learning Platform | Moodle.org, accessed on Feb. 29, 2016. [Online]. Available: https://moodle.org/

[23] EUPLA. (2015). Proceso de TFG. Escuela Universitaria Politécnica de La Almunia, accessed on Feb. 22, 2016. [Online]. Available: http:// www.eupla.unizar.es/files/docs/grados/TFG_dic_2013/procesotfg.pdf

[24] EUPLA. (2016). Plantillas TFG, accessed on Feb. 22, 2016. [Online]. Available: http://www.eupla.unizar.es/index.php/trabajos-fin-de-grado

[25] (2016). Zotero, accessed on Feb. 20, 2016. [Online]. Available: http://www.zotero.org/

[26] C. L. Nozal, J. F. D. Pastor, J. M. Raedo, and R. M. Sánchez, "Módulo Moodle para Gestionar Trabajos Final de Grado o Máster," IEEE Revista Iberoamericana Tecnologías Aprendizagem, vol. 7, no. 3, pp. 155-162, Aug. 2012.

[27] J. L. Green, G. Camilli, and P. B. Elmore, Eds., Handbook of Complementary Methods in Education Research. Washington, DC, USA: Lawrence Erlbaum Associates, 2006.

[28] A. B. Dellinger and N. L. Leech, "Toward a unified validation framework in mixed methods research," J. Mixed Methods Res., vol. 1, no. 4 pp. 309-332, Jan. 2007.

[29] J. E. Escaño, A. L. E. Sánchez, and M. L. S.-E. Lacleta, "Aprendizaje adaptativo en las aulas Moodle de TFG," in Proc. 3rd Congr. Int. Sobre Aprendizaje, Innov. Competitividad (CINAIC), 2015, pp. 726-731.

[30] Universidad de Cádiz. (2013). Evaluación de la Elaboración del Trabajo Fin de Grado. Encuesta Alumnos. [Online]. Available: http://www. uca.es/recursosgen/doc/Centros/CCMar/1816177068_562013103627.pdf

[31] M. L. Sein-Echaluce et al., "Design of adaptive experiences in higher education through a learning management system," in Proc. 3rd Int. Conf. Technol. Ecosyst. Enhancing Multiculturality, New York, NY, USA, 2015, pp. 165-171.

Javier Esteban-Escaño is currently a Professor of Automatic Control Systems with the Escuela Universitaria Politécnica de La Almunia, University of Zaragoza. He is an Active Member of the GIDTIC Research Group. His research currently focuses on the knowledge management on MOOCS and online adaptive learning.

Ana Lucía Esteban-Sánchez received the $\mathrm{Ph} . \mathrm{D}$. degree in information and documentation with the University of Zaragoza, in 2013, and the master's degree in free software from the Open University of Catalonia, in 2009. She is currently a Professor with the Escuela Universitaria Politécnica de La Almunia, College Area Electronics, Computer Science and Control, University of Zaragoza. Since 2014, she is a member of the Research and Innovation Group in Training supported by Information and Communication Technology (GIDTIC, Spanish abbreviation) Research Group, University of Zaragoza.

María Luisa Sein-Echaluce is Director of the Virtual Campus and Professor of Applied Mathematics with the School of Engineering and Architecture, University of Zaragoza. She is Principal Researcher with the GIDTIC Research Group. She is the President of the Scientific Committee at the International Conference of Learning, Innovation and Competitiveness (CINAIC, Spanish abbreviation) and sits on evaluation committees for calls for local innovation projects and for international conferences. Her research currently focuses on the application of technologies to cooperative methodologies and usage of open source LMS and other tools for online adaptive learning. 